\title{
Entrevista ao arquiteto Pere Buil
}

\author{
Filipa Ramalhete \\ framalhete@autonoma.pt \\ Centro de Estudos de Arquitetura, Cidade e Território da Universidade Autónoma de Lisboa \\ (CEACT/UAL), Portugal | Centro Interdisciplinar de Ciências Sociais da Universidade Nova de \\ Lisboa (CICS.Nova)
}

Rui Mendes

ruimiguelmendes@gmail.com

RM ARQUITECTURA

Para citação: RAMALHETE, Filipa; MENDES, Rui - Entrevista ao arquiteto Pere Buil. Estudo Prévio 15. Lisboa: CEACT/UAL - Centro de Estudos de Arquitetura, Cidade e Território da Universidade Autónoma de Lisboa, 2019. ISSN: 2182-4339 [Disponível em: www.estudoprevio.net]. DOI: https://doi.org/10.26619/2182-4339/15.4

Creative Commons, licença CC BY-4.0: https://creativecommons.org/licenses/by/4.0/

É com muito prazer que temos hoje connosco o arquiteto Pere Buil, de Barcelona. Começo por perguntar como foi o seu percurso académico. Sei que também passou por Portugal.

Estudei na Universidade Politécnica, em Barcelona. Durante o percurso académico não fui um grande estudante. Estava sempre envolvido noutras coisas, na área da política ou da cultura. Estes eram mais os meus interesses, além de mais, havia poucos professores que me estimulavam. Fiz Erasmus em Lisboa (tive o arquiteto Manuel Aires Mateus como professor de Projeto na FAUTL), e acabei por ficar cá. Finalizei o projeto de final de curso em Barcelona, apenas porque tinha que ser entregue lá. Não fiz mestrado nem doutoramento, comecei logo a trabalhar depositando toda a minha energia nisso.

\section{Isso foi logo após o fecho do curso, formaste um atelier imediatamente?}

De facto, eu comecei, já em Lisboa, a estudar e trabalhar, simultaneamente. Em Barcelona, era muito comum funcionar assim depois do terceiro ano. Os últimos anos do curso demoravam mais tempo, mas aprendíamos muito mais nos ateliers do que na escola... Durante o Erasmus, estive a trabalhar com o arquiteto austríaco Thomas Zinterl, que tinha atelier em Lisboa. E, quando estava a fazer o projeto final de curso, 
participei, com o Jordi Fornells, num concurso em Barcelona e ganhámo-lo, ainda antes de sermos arquitetos.

\section{O ateliê VORA nasce com esse concurso?}

Sim. O atelier começou comigo e com o Jordi, que acabou por ficar em Lisboa; eu, uns anos mais tarde, voltei a Barcelona. Trabalhámos ainda durante algum tempo juntos, mas à distância. Em 2005, entrou o Toni Riba, que é o terceiro sócio, e foi aí que surgiu o nome "vora". Eu e o Toni acabámos por ficar em Barcelona, e o Jordi desligou-se.

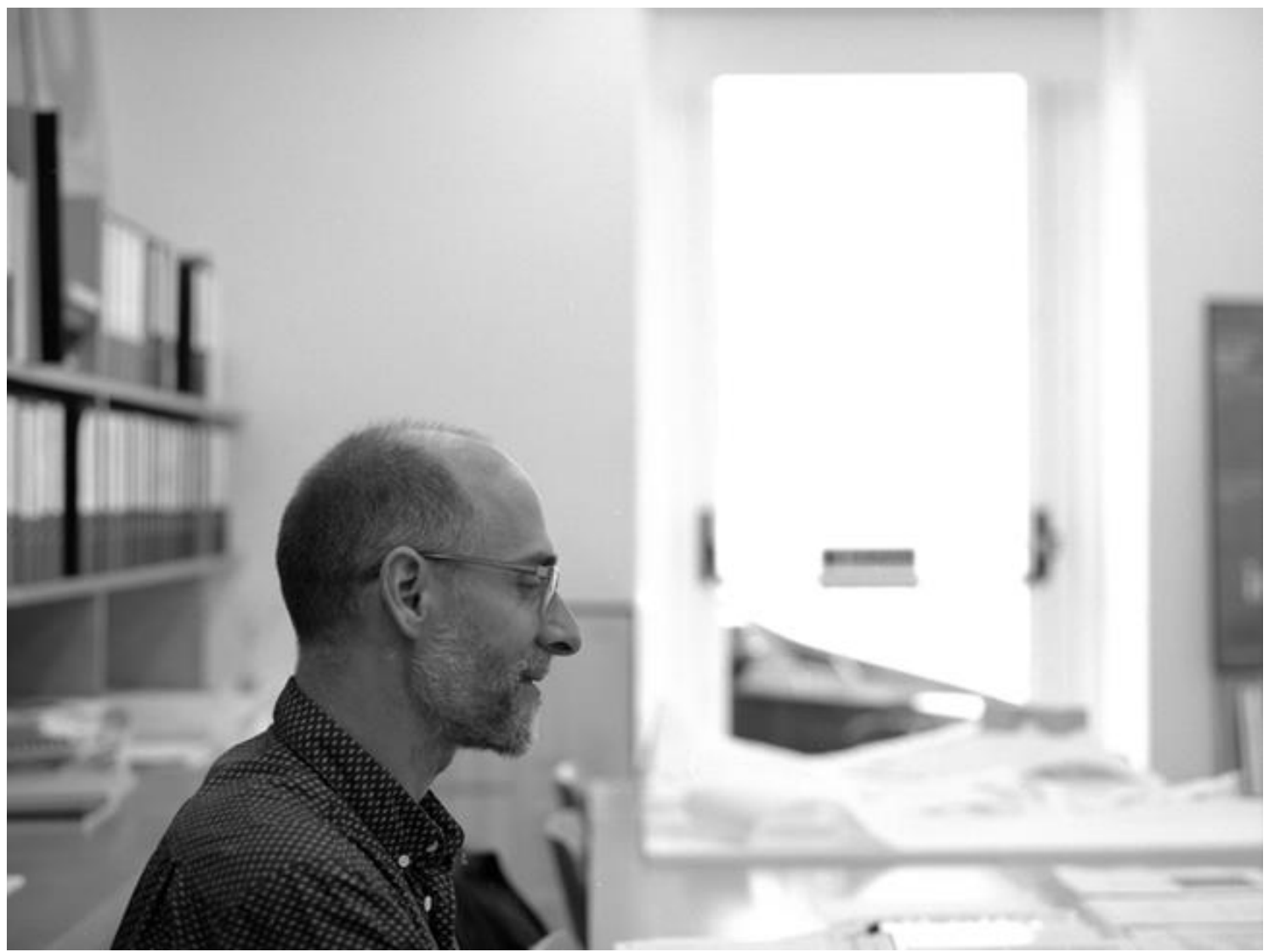

A maior parte dos arquitetos portugueses da nossa geração, que já entrevistamos, diz que a experiência da universidade não foi muito interessante. Parece que em Barcelona as coisas são parecidas... Terá sido uma época no ensino da arquitetura? Houve alguma experiência que tenha sido mais interessante ou mais estimulante, na universidade?

Sim, claro. Lembro-me de que em Barcelona tínhamos muitos bons professores de História e Composição. O António Pizza, o filósofo Xavier Rubert de Ventós, o Pedro Azara, o Juanjo Lahuerta... Eram pessoas muito interessantes e as suas aulas eram muito estimulantes. Também fiz uma disciplina de que gostei imenso, com o Elias Torres, uma disciplina opcional, de paisagismo em espaços urbanos. Ele era, e ainda 
é, uma personagem muito dinâmica. As suas aulas eram sempre interessantes e fazia os alunos pensarem muito, assumir posição. Esta foi, talvez, uma das minhas melhores experiências na escola. Também tive outra disciplina opcional de paisagismo, com a Rosa Barba, mais para trabalhar o conhecimento disciplinar numa área que não estava muito presente no currículo académico da escola. Era muito diferente das aulas do Elias Torres, mas também gostei muito. As disciplinas de projeto, em geral, eram dadas por professores que estavam na escola há muito tempo, e já numa fase em que não estavam com a mesma motivação...

\section{E o teu regresso à escola como professor acontece muito depois da experiência de aluno?}

Em 2010. De facto, eu tinha muito claro na minha cabeça que não queria ir logo para a escola, porque percebia que não tinha coisas para ensinar. Para mim, não fazia muito sentido fazer carreira académica logo após terminar o curso. Só uns anos depois é que comecei a ter essa inquietação, de querer enriquecer os outros, e a mim próprio também. Entrei na ETSALS (La Salle Barcelona), uma universidade privada, muito virada para o ensino da profissão e muito mais técnica, e fiquei lá uns anos. Mais tarde, entrei na universidade pública, na politécnica ETSAV, que é uma escola mais pequena - cada ano entram cerca de cem estudantes, que fazem trabalhos muito interessantes.

\section{E essa entrada foi através de convite ou por concurso?}

$\mathrm{Na}$ ETSALS entrei por convite. Chamou-me o arquiteto Pau Pérez, que coordenava a disciplina de Projeto de Arquitetura do segundo ano. O Pau é um magnífico arquiteto com uma posição ética em relação à arquitetura que admiro muito. Na universidade pública foi por concurso, há três anos.

Voltemos ao primeiro projeto, ganho através de concurso, que é o arranque do atelier e dos seus temas. Este concurso, para um centro desportivo com alguma dimensão para uns muito jovens arquitetos, formou bastante a ideia de trabalho do atelier.

Muito. Há muitas coisas daquele projeto que ainda estão presentes no nosso processo de pensamento e na forma como concretizamos os projetos. Foi engraçado, porque não tínhamos muita experiência, tínhamos trabalhado em ateliers durante os anos de estudo, mas nunca tínhamos ido a uma obra. Tínhamos desenhado muito, mas... E quando íamos a Barcelona, para ter reuniões na Câmara, dizíamos "sim, temos experiência, trabalhamos nestes ateliers, vamos às obras...". Mas o mais interessante foi que, quando começámos a obra, mesmo sem ter experiência, tínhamos muito mais conhecimento do que pensávamos. Tínhamos a certeza do que queríamos, dos objetivos do projeto e mesmo da construção. Podíamos falar ao mesmo nível com o empreiteiro. Foi um reflexo de que o ensino tinha sido positivo. Se calhar na altura da escola não estávamos muito motivados, mas tínhamos aprendido muitas coisas. Também tivemos professores de construção que eram muito bons e tinham um ensino muito sistemático, de conhecimento evolutivo, e acho que aprendemos muita coisa em relação ao tema da construção. 


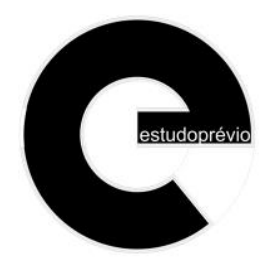

PT | E01 | EP15 | \$2019

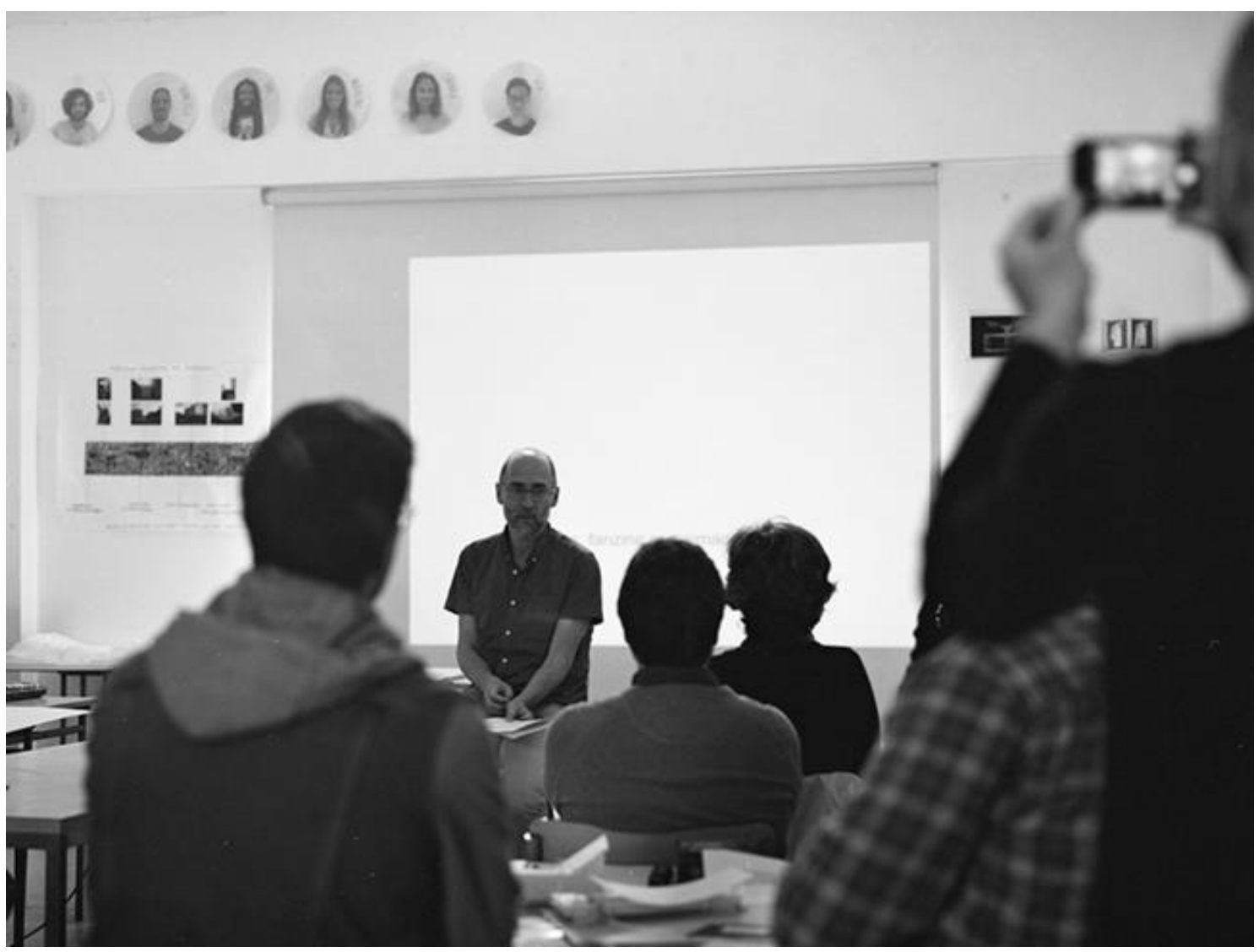

A esta distância também é possível perceber melhor, em conjunto com os trabalhos mais recentes, que o Can Ricart é um trabalho de espaço público muito importante; é um grande edifício de desporto, mas é sobretudo uma grande peça de espaço público.

Sim, todas as ligações do edifício com o contexto foram muito trabalhadas. Houve decisões importantes, por exemplo em relação ao acesso, que têm a ver com uma visão de ativação urbana. De facto, no concurso até propomos a cobertura acessível como prolongamento da atividade interior.

Depois, há uma coisa que também gostámos muito de trabalhar que foi a relação com a identidade do lugar, numa fachada que era enorme e cega (as piscinas normalmente são grandes volumes sem janelas, sem composição nenhuma). Gostamos de explorar a identidade dos contextos, por vezes mediante texturas que remetem para aspetos da memória. $\mathrm{E}$ isso começou a aparecer neste projeto.

Tu ensinas projeto. Os exercícios que propões aos alunos estão relacionados com esta prática do atelier? Podes dar o exemplo de alguns exercícios?

Nos anos anteriores, estive em estúdios que não eram coordenados por mim. Só este ano é que comecei a coordenar um estúdio com o nome de "Construir sobre o 
construído", que se relaciona com as nossas inquietações. Mas o estúdio é mais sobre um tema do que sobre uma mecânica de trabalho.

Eu acho que gosto mais de pôr os alunos em crise, e fazê-los pensar, do que dizerIhes os documentos que precisam de fazer, ou organizar-lhes o processo. Às vezes não fico muito satisfeito com o resultado, mas os que têm inquietações conseguem sempre evoluir e ganhar posição própria em relação a assuntos mais complexos, como a identidade, a memória ou aproveitamento.

\section{E as propostas são sobre que tipo de lugares?}

O primeiro quadrimestre foi sobre a Prisão Modelo de Barcelona, um edifício situado no centro da cidade, que foi encerrado recentemente e agora é uma infraestrutura obsoleta para a cidade. O exercício tinha o objetivo de fazer os alunos refletirem sobre o que era necessário fazer, em termos de uso (reprogramar), em termos do edifício (valor patrimonial e da memória coletiva) e entender a compatibilidade entre estas duas partes. Isto porque uma prisão é uma construção muito restrita e rigorosa. $\mathrm{O}$ objetivo deste estúdio, a médio-longo prazo, é passar por todo o tipo de trabalhos relacionados com preexistências e a memória acumulada, em diferentes situações ou contextos. Perceber o conflito entre valor histórico e aproveitamento versus necessidade de transformação $E$ tomar posição em relação a este conflito. Agora, no segundo estúdio, estamos a trabalhar sobre um parque arqueológico, onde a ideia é mais trabalhar sobre a maneira como as novas construções se agrupam, conceptualmente, com o passado arqueológico, que já não existe e que é só informação...

\section{E há sempre uma proposta de projeto?}

Sim. Pretende-se que haja uma reflexão sobre o programa, que não é fechado. Acho que os arquitetos deveriam possuir essa predisposição de refletir sobre o que é necessário para um lugar, qual a sua relação com o que existe à volta, qual o contributo para a sociedade. Na maioria dos casos, na realidade, não se pensa sobre isso, porque a encomenda ao arquiteto já define o programa. Mas é importante ter este nível de reflexão, nem que seja para manipular o programa sugerido, pô-lo em crise, ligá-lo mais às necessidades. De facto, é tao necessário que há arquitetos que só fazem programação e deixam de fazer arquitetura.

\section{Ainda no domínio da escola, o trabalho de coordenação desse atelier está relacionado com outros ateliers da escola - é horizontal ou a ligação com outras disciplinas é restrita?}

Na ETSAV todos os estúdios de projeto estão ligados com as outras disciplinas. Esta ligação é distinta em cada estúdio - com tecnologia, com história, com urbanismo. 


\section{estudoprévio}

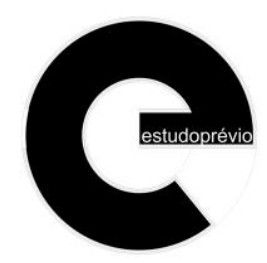

PT | E01 | EP15 | s2019

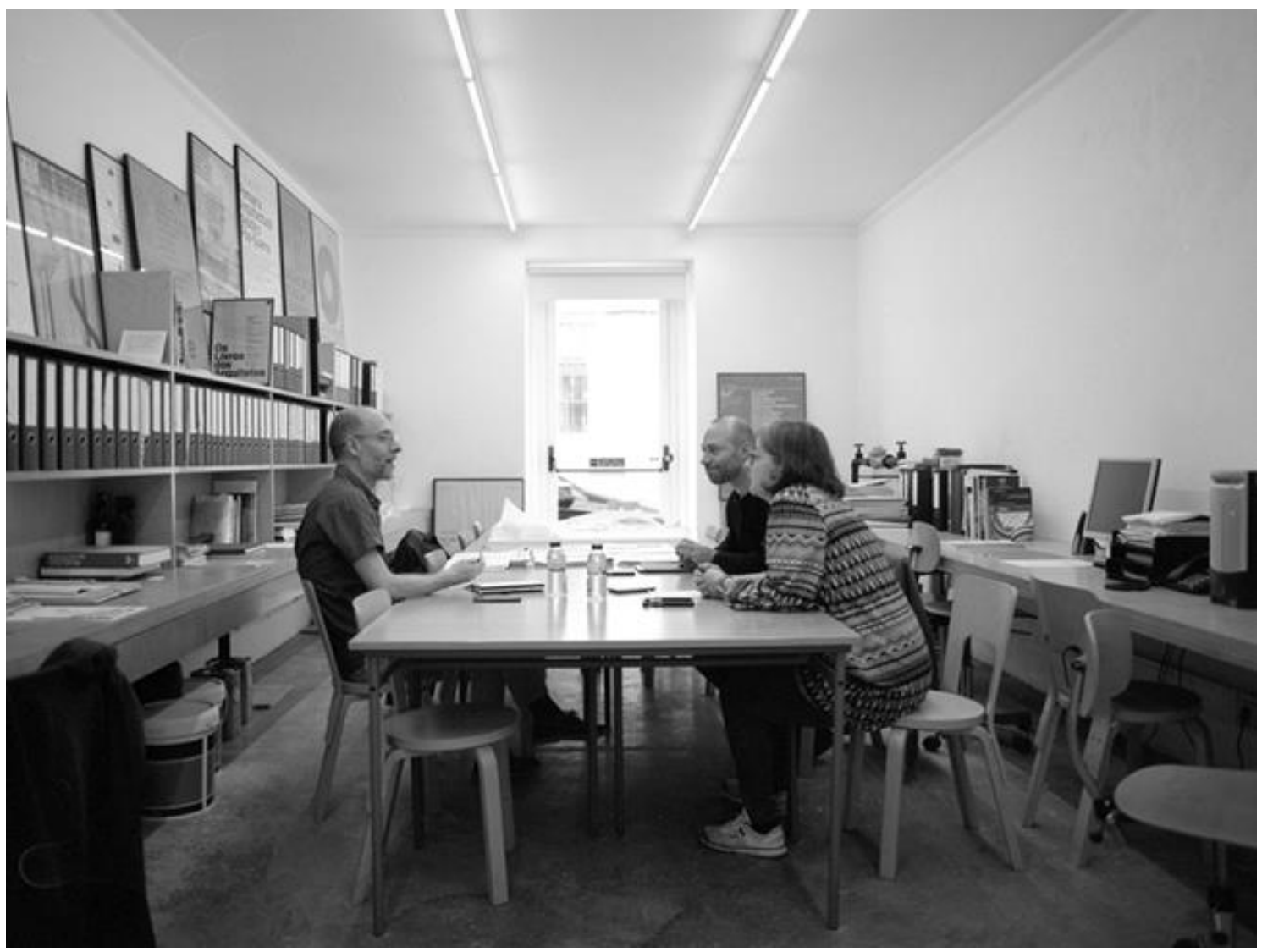

\section{E este seu estúdio?}

O meu estúdio é com História.

\section{Os estúdios têm sempre duas vertentes em paralelo?}

Os alunos podem escolher entre dois estúdios, a partir do terceiro ano. O outro estúdio, "paralelo" ao meu, também com História, é o do Xavier Vancells, que trabalha sobre a recuperação do património industrial de áreas abandonadas, normalmente territórios periféricos, mais à Cédric Price. A origem do meu estava mais ligada às questões patrimoniais. Mas eu estou a dar-Ihe um ar ligeiramente diferente. Os dois são um pouco complementares no programa da escola.

\section{Há muitos alunos internacionais?}

Até ao terceiro ano temos cerca de $10 \%$ e no quarto e quinto ano por volta de $20 \%$ / $30 \%$. 


\section{Quantos alunos trabalham nesse estúdio?}

No anterior, tive quarenta e, neste, tenho vinte. Os alunos inscrevem-se após uma apresentação do estúdio. Portanto tudo isto depende da oferta, da capacidade de sedução e do interesse dos alunos.

Nos últimos anos, no Da/UAL, temos diversificado muito a origem dos nossos alunos e tu, de alguma forma, és um pioneiro destas experiências internacionais; nos anos noventa isto era menos comum, ainda que houvesse o Erasmus, não tinha o impacto que tem hoje... Essa tua vontade de mudar de escola, de país, teve a ver com que referências?

Para mim, foi a cidade. Eu acho que comecei a ser arquiteto quando vim para Lisboa. Muitos estudantes têm o mesmo percurso: terminam o secundário, começam logo a universidade, dão continuidade a esta rotina académica. Tem de existir um momento qualquer de viragem, que nos faça pensar no porquê de estarmos a fazer algo. Para mim foi um pouco assim, e o facto de estar em Lisboa contribuiu para parar um pouco, graças à mudança de ritmo e de contexto. Deixei de morar em casa dos meus pais, pensei no que queria fazer na vida e no porquê de seguir arquitetura.

\section{Ainda trabalhaste com alguns arquitetos em Lisboa, não foi?}

Trabalhei com o Thomas Zinterl, um arquiteto austríaco que tinha duplo atelier (em Lisboa e em Áustria) e que colaborava com o Gonçalo Byrne. Depois trabalhei com o Gonçalo Byrne. Depois de ganhar o concurso, abrimos o atelier, que partilhámos durante um tempo com a Patrícia Barbas e, mais tarde, com o Rui Mendes. Na altura combinava o atelier com colaborações esporádicas com o Atelier Bugio. Aprendi imenso com todos, e tenho grandes memórias, ao nível pessoal e intelectual, do trabalho com os Bugio.

Neste momento, no atelier, mantêm esta lógica de coletivo internacional ou é um atelier mais clássico?

Eu acho que é bastante clássico. Somos dois associados, temos dois ou três arquitetos e mais um ou dois estudantes, que tentamos que sejam bastante estáveis, e vamos tendo também alguns internacionais, que passam lá uns meses, no mínimo seis. Trabalhamos bastante no nosso território. É o que conhecemos melhor e onde queremos contribuir com maior conhecimento. Ou talvez seja preguiça... Houve um período, durante a crise, em que participamos em alguns concursos na Suíça, e até ganhamos algumas menções, mas não chegámos a construir nada.

Pegando no grau de conhecimento que o atelier tem construído, é uma escolha deliberada, trabalhar sobre lugares cujo património, de alguma forma, é reconhecível para vocês?

Acho que não é muito propositado. Por vezes, também fazemos concursos para lugares que não conhecemos. Mas quando é um lugar que conhecemos, então fazemos um esforço maior ao trabalhar sobre ele. Nós temos trabalhado bastante no 
centro histórico de Barcelona, porque surgiram cadeias de relações: fazemos um projeto, gostam, ganham confiança no nosso trabalho, e surgem outras coisas. E, assim, nós também ganhamos conhecimento. Não é uma coisa pensada a priori, mas há um pouco essa atitude.

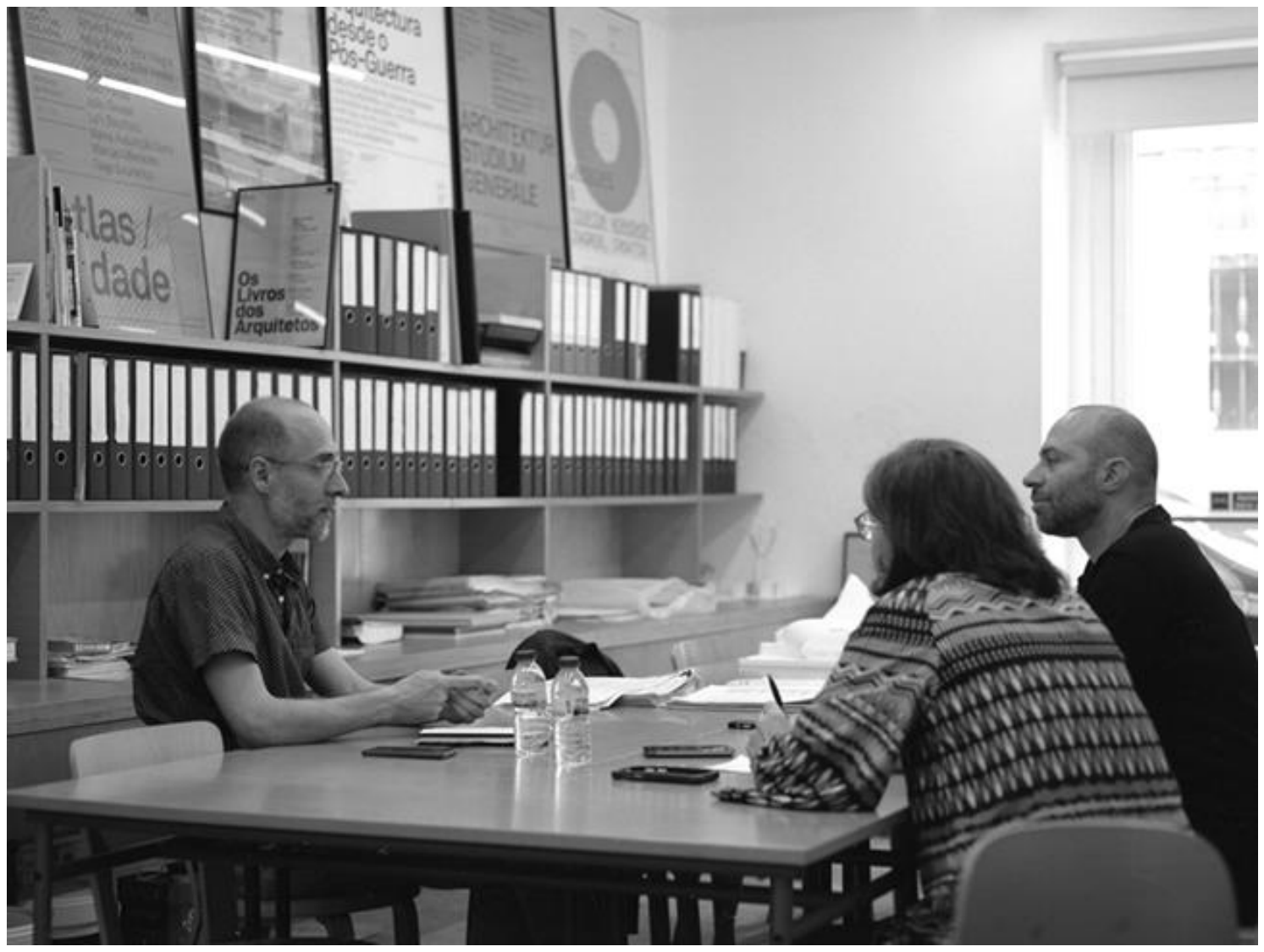

\section{Quais são os temas mais relevantes no trabalho que têm feito?}

Uma parte muito importante do trabalho é o nosso olhar sobre os espaços comuns, os espaços coletivos, em todas as suas escalas. Por exemplo, numa reabilitação de um pequeno apartamento, acabamos sempre por focalizar a nossa energia nos espaços de transição, para tentar que não sejam só isso, que tenham outra capacidade de uso. E transportamos essa ideia para o espaço público, procuramos conseguir que os espaços de encontro dos cidadãos tenham uma identidade própria e que sejam sentidos como seus. Esta linha de pensamento está um pouco presente em todos os projetos.

O outro foco do trabalho é sobre a memória e a identidade da obra, desde as caraterísticas de aproveitamento material - uma coisa comum entre os arquitetos da nossa geração - ao trabalho sobre as memórias desaparecidas, ou presentes mas não reconhecidas. Estas são as que constroem o mais profundo da identidade e que tentamos recuperar através do desenho. 


\section{Exemplifica alguns trabalhos que ilustrem isso.}

O projeto em redor do Mercado do Bairro de El Born. Trabalhámos sobre algo que está debaixo do chão e que faz, simultaneamente, parte da história, de um episódio trágico para cidade e para o país, e que não se entendia na forma da cidade atual.

Uma parte da cidade medieval foi destruída para se construir uma cidadela militar de controle sobre a cidade depois da guerra de sucessão (em que a Catalunha perdeu a independência). Em 1888, com a Feira Universal, demoliu-se a cidadela para se construir a cidade nova e o mercado, fantástico, de estrutura de fundição, e aquilo ficou lá por baixo enterrado. Quando se tentou construir uma biblioteca dentro do mercado, foi tudo descoberto. Nós tentamos que estes restos arqueológicos, que agora estão visíveis no interior do edifício, sejam compreendidos como parte integrante de um episódio da cidade e não como uma pequena joia fechada num baú. E tentamos transmitir isto no desenho dos pavimentos em redor do edifício.

\section{Fazer transparecer esse argumento na superfície do pavimento...}

Sim, e acrescentar também a relação com a memória do mercado e as arquiteturas à sua volta, do século XIX, a partir da pedra de granito (um material muito utilizado nos pavimentos dos espaços urbanos da cidade e que foi rejeitada, por questões funcionais, nos anos 80 , mas que faz parte do imaginário coletivo). Tentar que estas duas memórias recuperadas fiquem ali representadas.

Esse é um recurso muito comum do vosso escritório: reduzir muito o número de coisas, para mostrá-las melhor.

Sim, digamos que somos pouco barrocos. Fazemos um trabalho de síntese muito forte para enriquecer as ideias e, consequentemente, afirmar a sua complexidade, mas de maneira subtil.

Isso tem um pouco a ver com a questão da ligação da investigação com o projeto. Vocês trabalham com pessoas de outras disciplinas?

Sim, com historiadores, com arqueólogos - para além das típicas especialidades ligadas à arquitetura, mais técnicas. Porque de facto, não somos especialistas nem muito conhecedores de História. Necessitamos daqueles que tem esse conhecimento para o "digerirmos" para, à nossa maneira, o sintetizarmos e transformarmos de uma maneira mais livre. Os historiadores ficam muitas vezes presos ao conhecimento.

Se pensarmos um pouco no perfil dos nossos alunos e da geração que está agora a formar-se, em que as pessoas são tão móveis, pensas que será fácil manter esta postura de "arquiteto de uma cidade"? Neste momento, a circulação e flutuação tão intensiva de pessoas não propicia que se fique vinte anos a trabalhar num centro histórico... Essa leitura e pensamento sobre a cidade está, de certa forma, a diluir-se, eventualmente a criar coisas interessantes também. 
Penso que nós já somos muito diferentes das gerações anteriores, que tinham muitos projetos num raio de proximidade. Nós temos poucos projetos, e precisamos de depositar muita energia em cada um deles, e aprender muito em cada um. Não consigo imaginar como poderá ser com os mais jovens, num futuro próximo, mas acho que a relação com o lugar é muito inerente à nossa profissão. Precisamos sempre de fazer essa leitura. Doutro lado, o conhecimento também está aí, muito mais acessível.

Neste sentido, vocês podem tornar-se grandes conhecedores de um território, mas é exatamente por esse conhecimento muito forte que podem ser convidados a pensar sobre outros lugares.

Eu não me sinto nada erudito. Por exemplo, quando fazemos um projeto em Barcelona, não sinto que conheça aquilo muito bem, é mais uma atitude de curiosidade, de querer saber e de procurar as pessoas que sabem. $E$ isso pode-se fazer num novo sítio também.

Mas por exemplo, o João Gomes da Silva, que sabe imenso e faz conferências sobre Lisboa e que é de repente convidado para estar em Harvard e em Mendrisio, exatamente porque sabe muito sobre um território. Saber muito sobre um território é uma hipótese franca de conseguir aprender sobre outros.

Sim, constróis uma metodologia de aproximação à realidade, de leitura e de construção de conhecimento. Acho que o valor está no olhar do Gomes da Silva, mais do que o conhecimento enciclopédico. Ele desenvolveu esse olhar na sua profunda ação sobre o caso específico de Lisboa. Acho que nós estamos muito longe da sua capacidade.

Estava a lembrar-me de uns textos do Paulo Mendes da Rocha, em que ele fala sobre a casa que é a cidade e da cidade que é a casa... Quando vocês usam o argumento do pequeno e do grande, eu também vejo essa ideia de que o que é pequeno pode ser grande, e vice-versa. Como é que equilibram ou juntam a pequena reforma e este trabalho sobre o espaço público?

Em termos de trabalho conceptual, acabamos por trabalhar os espaços comuns, os espaços de articulação, os espaços de encontro. Estes são os que nos interessam mais. Acabamos por deixar um pouco de lado os quartos, as cozinhas, as casas de banho, e concentramos as energias na materialização destes outros espaços, na sua identidade, no seu conforto e na sua capacidade infraestrutural para que aconteçam coisas. O que é muito importante no espaço público também.

Em termos mais pragmáticos e de gestão do trabalho, isso depende das equipas que temos, e definimos a dinâmica consoante o momento no atelier. Muitas vezes trabalhamos nas duas escalas simultaneamente. Uma coisa pequena e, ao mesmo tempo, uma grande. 


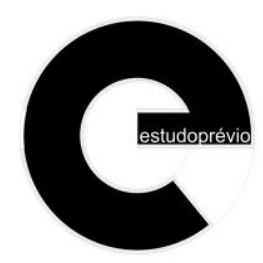

PT | E01 | EP15 | s2019

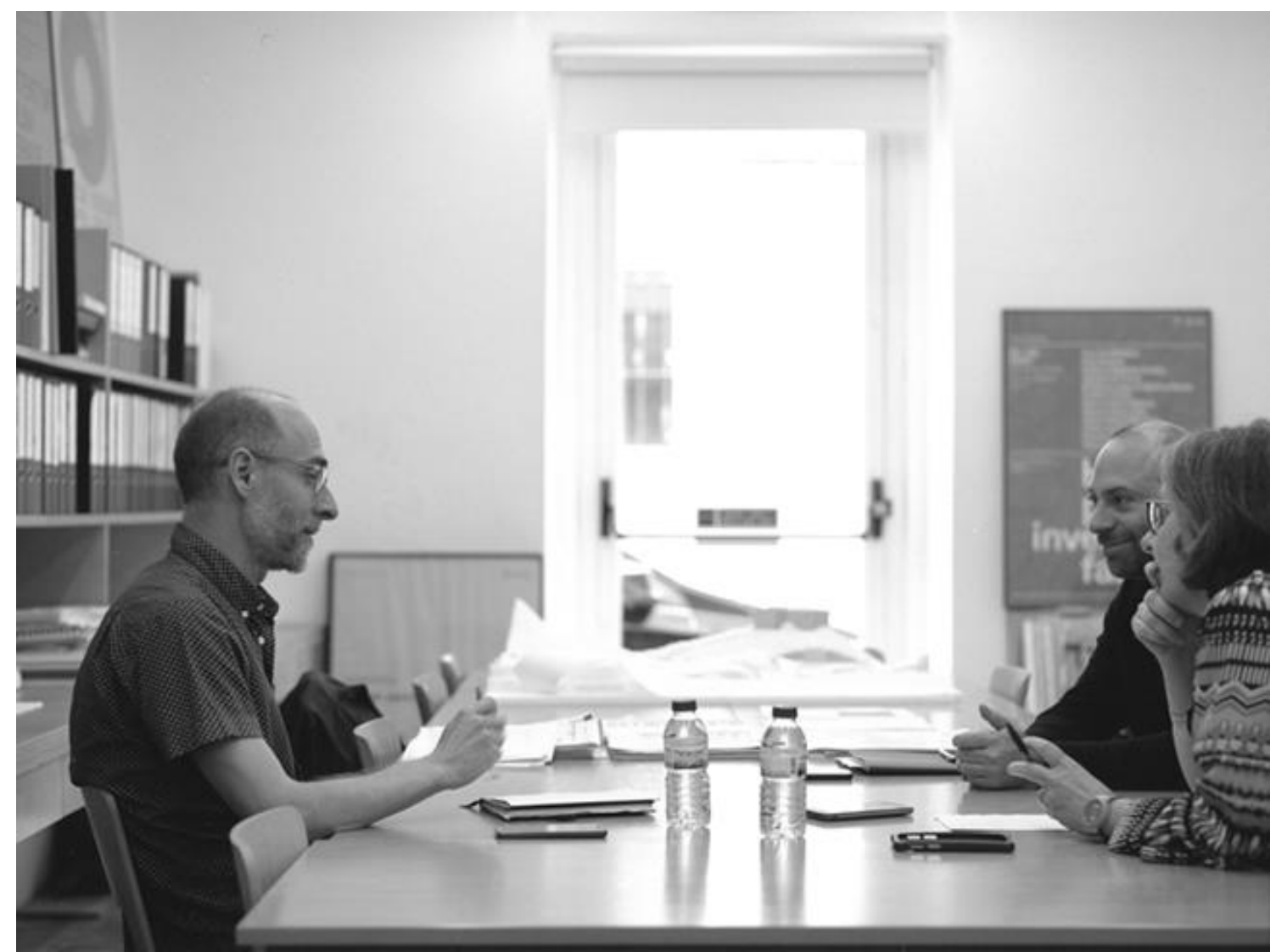

\section{E a relação da escola com o atelier, e do atelier com as curadorias que também fazes, como é que isso funciona?}

Isso tudo começou após algum tempo, no atelier. Quando começas, precisas de pôr muita energia nas coisas, na aprendizagem pela produção, precisas de ganhar mais conhecimento, é necessário muito tempo para criar qualquer coisa, porque tens muitas dúvidas. Portanto, a minha energia estava toda nisso. Mas, a certa altura, senti a necessidade de perceber porque é que estávamos a fazer as coisas e isso levou-me a organizar debates, encontros com outros arquitetos, o que mais tarde me conduziu à escola. Foram necessidades que fui tentando satisfazer, sem ter uma ideia clara de relação direta entre isto e o trabalho. Apenas para ter um espaço para o pensamento, um pensamento necessário para uma produção arquitetónica com sentido.

\section{Há uma experiência que consideramos importante e relevante, que é "Matéria sensível", podes falar um pouco dessa experiência?}

Foi uma curadoria que fiz com mais dois arquitetos, o Carlos Câmara e o Joan Vitòria. Foi num momento de mudança - em 2009, quando a crise estava a começar - e nós percebemos que havia uma nova geração, com outro olhar sobre a arquitetura; na Catalunha víamo-lo com muita clareza. Tentámos recolher isso, através de uma exposição e de uns encontros: fomos a Lisboa, a Berlim, à Corunha, fizemos intercâmbios com estes lugares para perceber se isto também estava a acontecer 
nesses sítios. Sem querer, propiciamos o encontro entre pessoas que estavam na mesma situação, na mesma linha de pensamento, o que contribuiu para um enriquecimento mutuo.

\section{E resultou nestes dois termos, “Matéria sensível”, porquê?}

"Matéria", porque nessa geração (ou grupo) havia uma aproximação muito material ao projeto, que pretendia gerar a forma e a imagem como resultado do processo construtivo, ou seja, o projeto não era um processo abstrato a priori mas sim um processo conjunto entre forma e matéria. "Sensível" por ser sensível ao ambiente, ao contexto, por ser sensível à habitabilidade: a questão da permeabilidade, a sensibilidade ao meio ambiente de uma maneira mais "natural" e não mecânica. Tudo isso era muito partilhado.

Inicialmente havia mais de cem ateliers, que vocês rastrearam, e depois escolheram dez, que levaram para encontros com outras geografias.

Escolhemos dez para fixar um número redondo, sem outra razão... Em cada sítio que fomos procurámos um local, um tradutor ou intérprete, que pudesse falar sobre nós naquele outro contexto; o Rui Mendes e o Ricardo Carvalho cá, o Andreas Ruby e os Somethingfantastic em Berlin, o Carlos Quintáns e o Carlos Pita na Corunha... Alguns daqueles arquitetos são agora muito conhecidos: os Bosch-Capdeferro, Harquitectes, TEd'A, Emiliano Lopez e Mónica Rivera... Eles contam que parte do seu crescimento resultou daí, destes encontros, que os fizeram enriquecer. $E$ a nós também.

\section{E depois acabam todos por fazer um trabalho juntos?}

Em 2013, a Câmara de Barcelona lançou um concurso para repensar a Praça das Glòries, que era um "buraco negro" da cidade. No plano do Ildefons Cerdà era para ser o centro da cidade, só que realmente ficou na fronteira entre a cidade habitada e a cidade industrial - o Poblenou. Ou seja, correspondia à periferia dos dois lados. Depois, acabou por ser um nó de circulação. O bairro industrial começou a ser mais "cidade", passou a ser mais habitado, mas é preciso construir essa ligação com o resto da cidade.

No concurso, os onze ateliers, apresentámo-nos todos em grupo e fomos selecionados para a segunda fase. $O$ trabalho baseado no debate coletivo propiciou a elaboração de uma proposta para repensar o modelo de cidade, num momento em que já se ponderava repensar estes assuntos.

O processo foi muito interessante. Debate sobre uma situação urbana que consideramos chave para repensar o modelo urbano. Também foi interessante em relação à gestão de um processo de pensamento e criação coletivo.

Daí resultou um livro, que compila esta proposta "manifesto" sobre o modelo de cidade, que no fundo é mais isso do que um projeto para um sítio específico. 
Isso até já se afasta um pouco do atelier tradicional. É engraçado essa visão, do atelier ser tradicional, mas depois a prática ser uma coisa tão diferente.

Isto são coisas que de vez em quando precisam de ser feitas.

Por último, queremos perguntar o que escolheste apresentar na conferência aqui na escola.

Vou falar dessa relação com a memória, através de vários projetos. Vou combinar alguns pequenos "exercícios" (contribuições para um fanzine que fizemos com uns amigos - de pensamento e especulação sobre episódios urbanos) com projetos construídos: o centro desportivo Can Ricart, a nossa primeira obra que já foi referida, a Domus Avinyó, uma atuação sobre um pequeno sítio arqueológico em Barcelona, o projeto de El Born, e o projeto do Banco de Espanha, em Madrid, que é o pátio logístico do edifício central, onde tentámos desenhar uma "grafia" que permite fundir e simultaneamente distinguir o espaço pedonal do espaço circulado, a partir da construção das notas de papel moeda.

Fotografias: @ Pedro Frade + Estudo Prévio 